\title{
Durvalumab Regimen
}

National Cancer Institute

\section{Source}

National Cancer Institute. Durvalumab Regimen. NCI Thesaurus. Code C160026.

An immunotherapy regimen consisting of durvalumab that may be used in the treatment

of bladder cancer and non-small cell lung cancer (NSCLC). 